\section{Accidental Needlestick Exposures linked to the Administration of Local Anesthesia by Healthcare Workers}

To the Editor-The Massachusetts Department of Public Health mandates that all Massachusetts hospitals maintain an active log to track sharps injuries due to the health risks related to such injuries. ${ }^{1}$ These logs are used to guide continuous quality improvement activities aimed at preventing sharps injuries. A review of sharps injuries at UMass Memorial Medical Center (UMMMC) in 2013 showed a seemingly high incidence occurring among healthcare workers who were administering local anesthesia. We undertook an investigation of the relative rate of needlesticks associated with local anesthesia administration compared to the rate of all sharps injuries over a 10 -year period.

A review was performed of all reported sharps injuries at UMMMC recorded in the Employee Health Services log between January 1, 2004 and December 31, 2013, including the setting of the event and the activity performed. Sharps injuries were categorized as 1 of 5 types: local anesthesia needlesticks, insulin needlesticks, other hollow-bore needlesticks (excluding local anesthesia and insulin sticks), suture injuries, and scalpel injuries. Sharps injuries per 1,000 employees were calculated using the total number of employees, residents, and medical students per year. Sharps injury rates per 10,000 inpatient days were also calculated using the total inpatient admissions, ambulatory visits, and emergency department visits per year. We used descriptive statistics, test of trend, and $U$ statistical process control charts to describe the sharps injury incidence over time.

There was a statistically significant decrease in overall sharps injuries per 1,000 employees from 2004 to $2013(P=.003)$ (Table 1). In contrast, sharps injuries associated with local anesthesia needlesticks showed a statistically significant increasing trend from 2004 to $2013(P=.017)$. Other hollowbore needlesticks showed a statistically significant decreasing trend from 2004 to 2013. The incidence of insulin needlesticks, suture injuries, and scalpel injuries showed no significant trend from 2004 to 2013. Comparable trends are shown with calculated rates per 10,000 inpatient days.

Accidental sharps injuries put healthcare workers at risk for $>20$ pathogens, including HIV, hepatitis B, and hepatitis C. ${ }^{2,3}$ In addition to the concern for healthcare workers well-being, exposure management incursa significant cost to healthcare, with cost estimates of well over $\$ 100$ million annually in the United States. ${ }^{4,5}$ Consequently, continued efforts to identify and eliminate the causes of sharps injuries are essential.

Sharps injuries can result from the exchange of sharps between healthcare workers, the placement of sharps in the disposal container, or nonadherence to the sharps injury prevention protocol. ${ }^{1,6,7}$ Sharps injury can be prevented by eliminating unnecessary sharps use, the use of sharps injury prevention devices, the practice of safer work environments, and continuous training of healthcare workers regarding proper technique and safety. ${ }^{1}$ Data from the Massachusetts Department of Public Health have shown an ongoing decline in sharps injuries across all Massachusetts hospitals that correlates with the introduction of these approaches. ${ }^{1,8}$

Practices that have been linked to healthcare worker injuries from hollow-bore needles include not properly recapping the needle, lack of awareness of needle location in relation to oneself, and/or not activating safety mechanisms to cover the tip of the needle. ${ }^{6,7}$ An association between the administration of local anesthesia and sharps injuries has not previously been noted, but it is reasonable to consider that it relates to the procedure used to administer local anesthesia. To administer local anesthesia, the healthcare worker commonly draws up excess local anesthesia in to a syringe, performs an initial injection of local anesthetic, places the needle and syringe down with or without capping the needle, and then reuses the same needle and syringe to administer additional doses of local anesthesia as needed to

TABLE 1. Sharps Injuries per 1,000 Employees

\begin{tabular}{|c|c|c|c|c|c|c|c|}
\hline Year & $\begin{array}{l}\text { Total Sharps } \\
\text { Injuries, No. } \\
(95 \% \mathrm{CI})\end{array}$ & $\begin{array}{c}\text { Local } \\
\text { Anesthesia } \\
\text { Sticks, No. } \\
(95 \% \text { CI })\end{array}$ & $\begin{array}{c}\text { Insulin } \\
\text { Sticks, No. } \\
(95 \% \text { CI })\end{array}$ & $\begin{array}{l}\text { Other Hollow- } \\
\text { Bore Needle } \\
\text { Sticks, No. } \\
(95 \% \text { CI })\end{array}$ & $\begin{array}{l}\text { Non-Hollow- } \\
\text { Bore Needle } \\
\text { Sticks, No. } \\
(95 \% \mathrm{CI})\end{array}$ & $\begin{array}{c}\text { Suture Injuries, } \\
\text { No. }(95 \% \text { CI })\end{array}$ & $\begin{array}{c}\text { Scalpel } \\
\text { Injuries, No. } \\
(95 \% \mathrm{CI})\end{array}$ \\
\hline 2004 & $36.6(32.0-41.2)$ & $1.79(0.8-2.8)$ & $0.89(0.2-1.6)$ & $14.43(11.6-17.3)$ & $4.02(2.5-5.5)$ & $11.16(8.6-13.7)$ & $2.68(1.4-3.9)$ \\
\hline 2005 & $34.89(30.5-39.1)$ & $1.31(0.5-2.2)$ & $0.58(0.0-1.2)$ & $15.18(12.3-18.1)$ & $4.67(3.1-6.3)$ & $9.93(7.6-12.3)$ & $2.04(1.0-3.1)$ \\
\hline 2006 & $28.9(25.0-32.9)$ & $1.82(0.8-2.8)$ & $0.98(0.3-1.7)$ & $10.66(8.3-13.1)$ & $4.63(3.1-6.2)$ & $7.99(5.9-10.1)$ & $2.24(1.1-3.3)$ \\
\hline 2009 & $30.78(26.9-34.7)$ & $2.57(1.4-3.7)$ & $1.41(0.6-2.2)$ & $9.36(7.2-11.5)$ & $3.98(2.6-5.4)$ & $9.36(7.2-11.5)$ & $2.69(1.5-3.9)$ \\
\hline 2010 & $28.54(24.8-32.3)$ & $2.68(1.5-3.8)$ & $0.51(0.0-1.0)$ & $9.43(7.3-11.6)$ & $2.55(1.4-3.7)$ & $9.43(7.3-11.6)$ & $2.8(1.6-4.0)$ \\
\hline 2011 & $27.97(24.2-31.7)$ & $1.57(0.7-2.5)$ & $0.79(0.2-1.4)$ & $7.62(5.7-9.6)$ & $4.46(3.0-6.0)$ & $9.59(7.4-11.8)$ & $3.81(2.4-5.2)$ \\
\hline 2012 & $27.27(23.5-31.0)$ & $2.69(1.5-3.9)$ & $0.54(0.0-1.1)$ & $8.33(6.3-10.4)$ & $4.84(3.3-6.4)$ & $7.78(5.8-9.8)$ & $2.28(1.2-3.4)$ \\
\hline 2013 & $27.09(23.2-31.0)$ & $3.75(2.3-5.2)$ & $0.58(1.0-1.1)$ & $7.64(5.6-9.7)$ & $3.17(1.9-4.5)$ & $8.64(6.5-10.8)$ & $2.31(1.2-3.4)$ \\
\hline
\end{tabular}


obtain adequate analgesia for a subsequent procedure. Therefore, the safety mechanism on the needle and syringe are not activated after the first use, and healthcare workers may become injured when recapping the needles or by being unaware of the needle location. ${ }^{6}$

The reasons for the increase in the incidence of injuries associated with local anesthesia administration at our institution is not clear. It is possible that these events were underreported in the past, and that more accurate reporting occurred in relation to the overall decrease in the rate of sharps injuries. Strengths of this study include the study population and duration: our analysis included sharps injuries over 10 years at a large academic medical center and included events in both the inpatient and outpatient settings. Two limitations of this study are the retrospective study design and its setting in an academic medical center, which may not be generalizable to other settings.

In summary, we report a previously unidentified risk factor for sharps injuries, the administration of local anesthesia by healthcare workers. Further research is needed to develop effective counter measures to prevent these injuries.

\section{ACKNOW LEDGMENTS}

Financial support. None reported.

Potential conflicts of interest. All authors report no conflicts of interest relevant to this article.

Hannah Martin, $\mathrm{MD}^{1}$ Christina Hermos, MD; ${ }^{1,2}$ Constance M. Barysauskas, $\mathrm{MS}^{3}$ Susan Bradbury, RN, MSPH, CIC; ${ }^{4}$ Susan Sullivan, RN, BSN; ${ }^{5}$ Richard T. Ellison III, MD $\mathrm{MD}^{1,4,6}$

Affiliation: 1. University of Massachusetts Medical School, Worcester, Massachusetts; 2. Department of Pediatrics, Division of Infectious Diseases, UMass Memorial Children's Medical Center, Worcester, Massachusetts; 3. Department of Biostatistics and Computational Biology, Dana-Farber Cancer Institute, Boston, Massachusetts; 4. Department of Infection Control, UMass Memorial Medical Center, Worcester, Massachusetts; 5. Department of Employee Health Services, UMass Memorial Medical Center, Worcester, Massachusetts; 6. Department of Medicine, Division of Infectious Diseases, University of Massachusetts Medical School, Worcester, Massachusetts.

Address all correspondence to Hannah Martin, 14 Trumbull St. New Haven, CT06511 (hcmartin11@gmail.com).

PREVIOUS PRESENTATION: This article was previously presented at IDWeek 2014, October 8-12, 2014, in Philadelphia, Pennsylvania. Infect. Control Hosp. Epidemiol. 2015;36(12):1487-1488

(C) 2015 by The Society for Healthcare Epidemiology of America. All rights reserved. 0899-823X/2015/3612-0029. DOI: 10.1017/ice.2015.229

\section{REFERENCES}

1. Laramie AK, Pun VC, Fang SC, Kriebel D, Davis L. Sharps injuries among employees of acute care hospitals in Massachusetts, 2002-2007. Infect Control Hosp Epidemiol 2011;32:538-544.
2. De Carli G, Abiteboul D, Puro V. The importance of implementing safe sharps practices in the laboratory setting in Europe. Biochem Med (Zagreb) 2014;24:45-56.

3. Occupational Safety and Health Administration (OSHA). Occupational exposure to bloodborne pathogens; needlestick and other sharp injuries; final rule. Federal Register 2001;66:5317-5325.

4. Leigh JP, Gillen M, Franks P, Sutherland S, Nguyen HH, Steenland K, et al. Costs of needlestick injuries and subsequent hepatitis and HIV infection. Curr Med Res Opin 2007;23: 2093-2105.

5. Adib-Hajbaghery M, Lotfi MS. Behavior of healthcare workers after injuries from sharp instruments. Trauma Mon 2013;18:75-80.

6. Jagger J, Hunt EH, Brand-Elnaggar J, Pearson RD. Rates of Needle-Stick Injury Caused by Various Devices in a University Hospital. New Engl J Med 1988;319:284-288.

7. Bi P, Tully PJ, Pearce S, Hiller JE. Occupational blood and body fluid exposure in an Australian teaching hospital. Epidemiol Infect 2006;134:465-471.

8. Sharps injuries among hospital workers in Massachusetts: Findings from the Massachusetts sharps injury surveillance system, Boston, MA: U.S. Occupational Health Surveillance Program. Massachusetts Department of Public Health Website. http://www. mass.gov/eohhs/docs/dph/occupational-health/injuries/injurieshospital-2012.pdf. Published 2012. Accessed May 28, 2014.

\section{Cluster of Puerperal Fever in an Obstetric Ward: A Reminder of Ignaz Semmelweis}

To the Editor-Postpartum infections have decreased over the last hundred years; however, infections still cause approximately $13 \%$ of pregnancy-related deaths. ${ }^{1}$ Group-A Streptococcus (GAS) is an uncommon but serious and potentially preventable cause of postpartum infection. The laboring woman is especially vulnerable to invasive GAS infection acquired via disrupted mucosal or cutaneous barriers during delivery. ${ }^{2}$ Outbreaks of postpartum GAS infection continue to be reported and are often related to the spread of GAS among postpartum patients by asymptomatic colonized healthcare workers (HCWs). ${ }^{2}$

In May 2012, the Hadassah Hospital Clinical Microbiology Laboratory informed the infection prevention team that GAS had been isolated from vaginal and blood specimens of 2 women, who had vaginal deliveries a few days earlier. In according with Centers of Disease Prevention and Control (CDC) recommendations, ${ }^{3}$ an epidemiological investigation was initiated. A search was conducted to identify additional cases of GAS in the ward; none were found. All HCWs involved in taking care of the 2 women were identified and submitted a throat swab for GAS culture. A midwife who was present at the 2 deliveries tested positive for GAS. She reported having recently had a throat infection that was treated with antibiotics. The susceptibility patterns of all isolates, from the 